\title{
Metal Oxides-Based Semiconductors for Biosensors Applications
}

\author{
Ionel Şerban and Alexandru Enesca* \\ Product Design, Mechatronics and Environmental Department, Transilvania University of Brasov, Brasov, Romania
}

The present mini review contains a concessive overview on the recent achievement regarding the implementation of a metal oxide semiconductor (MOS) in biosensors used in biological and environmental systems. The paper explores the pathway of enhancing the sensing characteristics of metal oxides by optimizing various parameters such as synthesis methods, morphology, composition, and structure. Four representative metal oxides $\left(\mathrm{TiO}_{2}, \mathrm{ZnO}, \mathrm{SnO}_{2}\right.$, and $\left.\mathrm{WO}_{3}\right)$ are presented based on several aspects: synthesis method, morphology, functionalizing molecules, detection target, and limit of detection (LOD).

Keywords: metal oxides, semiconductors, nanostructures, energy bands, biosensors

\section{INTRODUCTION}

Biosensors represent key components in medical care, environmental processes, energy efficient systems, food safety, chemical, and agricultural industries. The necessity of using continuous onsite

OPEN ACCESS

Edited by:

Liwei Wang,

Guangxi University, China

Reviewed by:

Zhongqiu Hua,

Hebei University of Technology, China

Liping Gao,

Chuzhou University, China

*Correspondence:

Alexandru Enesca

aenesca@unitbv.ro

Specialty section:

This article was submitted to

Nanoscience,

a section of the journal

Frontiers in Chemistry

Received: 04 February 2020

Accepted: 06 April 2020

Published: 19 May 2020

Citation:

Şerban I and Enesca A (2020) Metal Oxides-Based Semiconductors for

Biosensors Applications.

Front. Chem. 8:354.

doi: 10.3389/fchem.2020.00354 monitoring with flexible and reliable characteristics have recommended biosensors as an efficient tool for rapid measurement and analysis. Adapting the biosensors materials to various applications (quality control, screening methods, safety equipment, environmental evaluation) represents an important research topic with difficult challenges to overcome. In the last decade there were many papers presenting materials such as photonic crystals (Hocini et al., 2019), polymers (Gupta et al., 2020), graphene (Yuan et al., 2019), metals (Rezaei et al., 2019), transition metal dichalcogenties (Wang et al., 2017), and metal organic frameworks (Osman et al., 2019) as suitable for biosensors applications. Some of these materials require significant improvement regarding morphologic optimization, chemical stability, compatibility with different biomolecules, and increase of LOD.

A particular case is represented by MOS materials. These have a high potential to become highly competitive materials in the biosensors market, based on their morphologic versatility (Song et al., 2020), chemical stability (Hernández-Cancel et al., 2015), physicochemical interfacial properties (Scognamiglio et al., 2019), and their ability to combine in composite structures (Zheng et al., 2020). Among others, $\mathrm{TiO}_{2}$ (Wang M. et al., 2019), $\mathrm{WO}_{3}$ (Liu et al., 2015), $\mathrm{SnO}_{2}$ (Dong and Zheng, 2014), and $\mathrm{ZnO}$ (Zhang et al., 2019) have attracted considerable attention due to their electrochemical sensitive properties (Enesca et al., 2012a) and energy band alignment (Enesca et al., 2012b) suitable for enzyme based biosensors. Another advantage of these materials is represented by a large number of cost effective synthesis methods such as co-precipitation (Dong and Zheng, 2014), sonochemical precipitation (Zhou et al., 2013), thermal oxidation (Li et al., 2010), chemical etching (Liu et al., 2010), polyol (Elahi et al., 2019), hydrothermal (Zhou et al., 2017), or sol-gel (Rathinamala et al., 2019) allowing the formation of various morphologies such as porous quasi-nanospheres (Liu H. et al., 2017), hollow nano-spheres (Santos et al., 2016), nanorods (Dong et al., 2017), nanosheets (Zhang et al., 2020), or flower-like particles (Feng et al., 2018). Additionally, these materials can be combined between them or with others to form tandem heterostructures (Enesca et al., 2015), hybrid structures (Mihaly et al., 2008), or composite structures (Visa et al., 2016) with advanced electrochemical properties which can be adapted to a specific biosensor application. 
MOS with multifunctional properties able to monitor molecules from biological systems represent a step forward in the development of more complex autonomous medical decision-making systems. Enzyme-based biosensors containing MOS have several advantages such as: (1) chemical stability in various environments (Zheng et al., 2020), (2) high energy efficiency (Solaimuthu et al., 2020), (3) good sensitivity (Yi et al., 2020), and (4) adaptability to specific working conditions (Han et al., 2019). There are several issues to overcome in order to implement MOS in biosensing applications: organic/inorganic interface compatibility, increasing the carrier charge mobility, decreasing electron-hole recombinations, and finding facile synthesis techniques.

The present mini review represents a synthesis of the recent achievement of the implementation and optimization of MOS used as biosensor components in biological and environmental systems. The paper is focused on various methods of enhancing the metal oxides' sensing characteristics by optimizing parameters such as synthesis methods, morphology, composition, and structure.

\section{THE MECHANISM OF ENZYME-BASED BIOSENSORS}

A biosensor structure (see Figure 1) can be broken down in a biotransducer and its auxiliary signal processing elements (Yin et al., 2018). The biotransducer is made up of a biocompatible layer that has biological recognition entities (enzymes, probe molecules, proteins, etc.) attached to the transducer surface. These entities induce a physicochemical interaction between the target analyte and the transducer, sending signal impulses to the signal processor. An important challenge represents the compatibility between metal oxide inorganic materials with the organic material Wang Q. et al., 2019; Yilmaz et al., 2020. In this sense $\mathrm{MOS}$ (i.e., $\mathrm{TiO}_{2}$, $\mathrm{WO}_{3}, \mathrm{SnO}_{2}, \mathrm{ZnO}$ ) functionalization in order to increase the compatibility with the organic materials has attracted much interest. The metal oxide semiconductors present some advantages regarding biomolecule immobilizations, such as: (a) high isoelectric point (IEP) which induces electrostatic attraction forces with many lower electrostatic point biomolecules (RamonMarquez et al., 2018; Zhao et al., 2019) and (b) morphological versatility exhibited by a high surface area-to-volume ratio characteristic for nanomaterials and favorable for enzyme immobilization, (Fiorani et al., 2019).

Most of the metal oxides materials used in biosensors are wide band gap semiconductors (see Figure 1) consisting of various crystalline structures, unique electrochemical, optical, electronic, gravimetric, pyroelectric, and piezoelectric properties (Huang et al., 2016). Surface potential represents an important property in the biosensor application. The space charge effect is a result of native and imposed semiconductor potential. The bulk chemical composition, crystallization degree, and chemical interaction between semiconductor surface and the analyte will influence the displacement of Fermi energy and induced depletion (Cao et al., 2020). Consequently, the surface potential inducing the space charge double layer is directly dependent on the adsorbed layer characteristics of the electrode surface (Chen et al., 2019). Additionally, some of these materials may exhibit super hydro -phobicity/philicity, self-cleaning and antimicrobial activity. Other factors such as light exposure at certain wavelengths $\left(\sim 380 \mathrm{~nm}\right.$ for $\mathrm{TiO}_{2}$ and $\mathrm{ZnO}, \sim 320 \mathrm{~nm}$ for $\mathrm{SnO}_{2}$ and $\sim 443 \mathrm{~nm}$ for $\mathrm{WO}_{3}$ ) induce an increase of charge carrier mobility. During the light irradiation, oxygen vacancies are formed at the semiconductor surface, which can forward develop oxidative species (Ge et al., 2019).

An important advantage in the metal oxides semiconductor functionalization for biosensor application is represented by the low toxicity and low probability of negative interference with the common pharmaceutical compounds (Soldatkina et al., 2018). The major functionalization methodologies are based on covalent interactions (Feizabadi et al., 2019) but non-covalent interactions have been used as well (Ortiz et al., 2019). The covalent conjugation can be done using different molecules such as dimercaptosuccinic acid (DMSA), 1-ethyl3-(3-dimethylaminopropyl) carbodiimide), (EDC), N-(15carboxypentadecanoyloxy) succinimide, 16-(2-pyridyldithiol) hexadecanoic acid, etc. During the functionalization the MOS became more stable and reduced the nanoparticles aggregation, (Xu et al., 2020). After functionalization many analytes can be used as detecting materials for: urea, immunoglobulin, DNA, RNA, dopamine, cancer cells, viruses, etc.

The interactions between the bio-transducer and the analytes will alter the physico-chemical surface semiconductor characteristics. The surface potential, impedance or current characteristics can be correlated with the specific chemical stimuli induced by the analytes (Yoo et al., 2019). Various techniques are based on these characteristics, such as cyclic voltametry, impedimentric, differential pulse voltametry, etc.

The fidelity of the results from such a biosensor are however heavily influenced by the environmental factors of the experiment, such as temperature, humidity, $\mathrm{pH}$, presence of oxygen, and foreign organic compounds, all of which can affect the stability of the interface. The applications of such biosensors spread across all domains, depending on the possible interactions between the immobilized biomolecules (enzymes, antibodies, DNA) and the analytes of interest.

\section{METAL OXIDE SEMICONDUCTORS FOR ENZYME-BASED BIOSENSORS}

There are various MOS's used in biosensor applications. The majority part use mono-component semiconductors but there are many papers (Oh et al., 2013; Kao et al., 2015) presenting multi-component semiconductors or coupled semiconductors (composite, tandem, heterostructures, etc.). Additionally, in order to enhance certain properties these materials have been coupled with metals nanoparticles or doped with other metal ions. The MOS exhibit a multitude of morphologies such as: rods, stars, flowers, cone, porous or dense films, etc. This mini review will consider only four metal oxides $\left(\mathrm{TiO}_{2}, \mathrm{SnO}_{2}, \mathrm{ZnO}\right.$, 


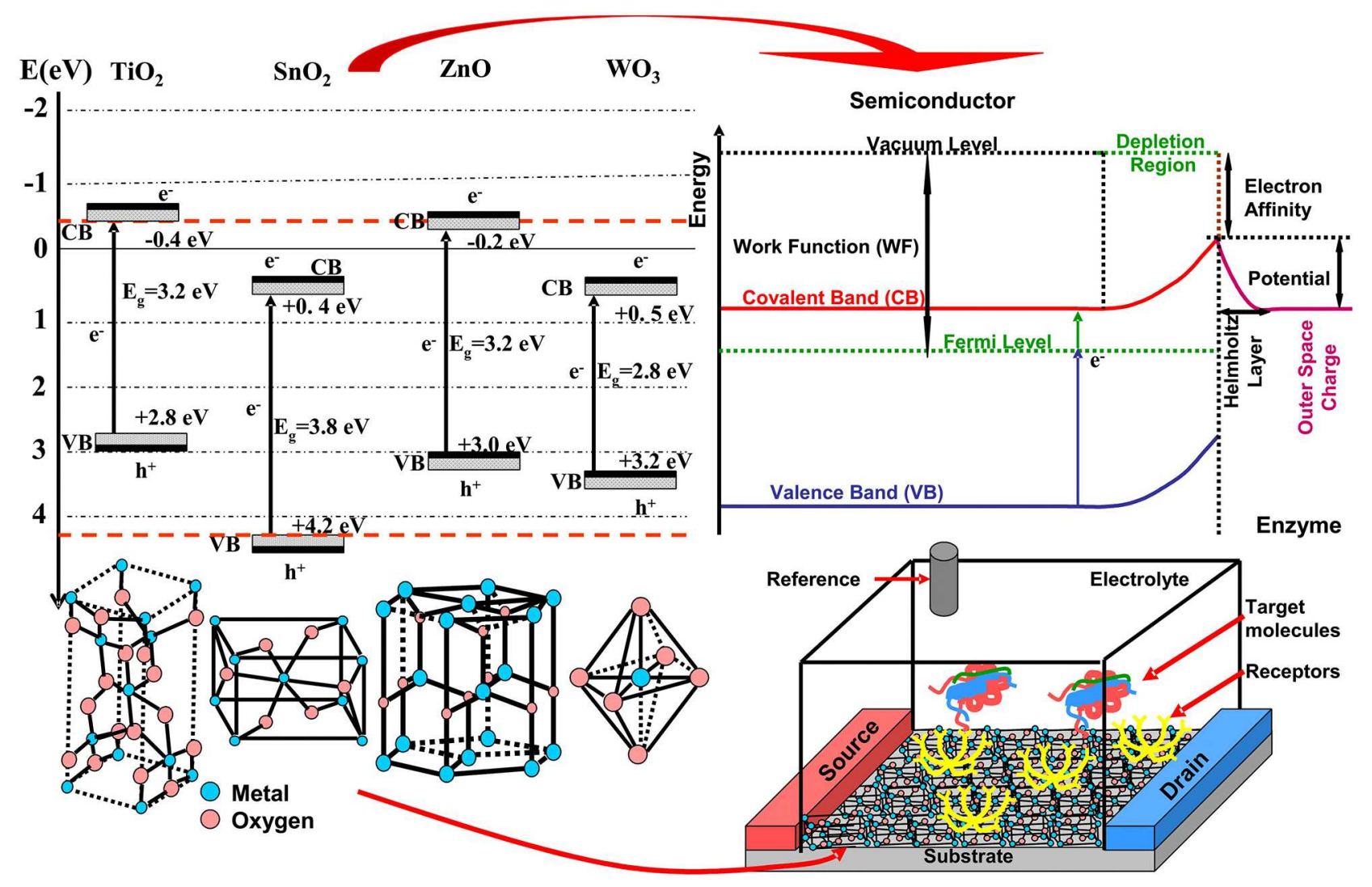

FIGURE 1 | MOS used in biosensors: band energies, crystalline structure, and biosensor configuration.

and $\mathrm{WO}_{3}$ ) as representative for biosensor applications. Many other papers which are not included here have the potential to contain highly innovative work. A summarized data collection containing the four metal oxides is presented in Table 1.

\section{$\mathrm{TiO}_{2}$-based Biosensors}

$\mathrm{TiO}_{2}$ is an n-type semiconductor considered as a key material in many applications like photocatalysis, biosensors, photovoltaics, or energy storage due to his properties such as high chemical stability, biocompatibility, morphological versatility, etc.

Dip-coating technique was employed to obtain $\mathrm{TiO}_{2}$ films serving as sensors for microRNA (Wang M. et al., 2019), heme (Çakiroglu and Özacar, 2019), or glucose (Rajendran et al., 2018). The microRNA sensor is based on black $\mathrm{TiO}_{2}$ deposed on indium tin oxide (ITO) substrate and improved with Au nanopoarticles. The semiconductor was functionalized with histostar antibodies and based on photocurrent measurements the LOD was established at $0.13 \mathrm{fM}$. Photocurrent was used for LOD evaluation of heme using $\mathrm{TiO}_{2} /$ ITO sensitized with CdS quantum dots, and the result was $19 \mu \mathrm{M}$. The glucose detector based on $\mathrm{TiO}_{2}$ film was functionalized with glucose oxidase (GOx) and the LOD was $0.7 \mu \mathrm{M}$. A better LOD value $(0.5 \mu \mathrm{M})$ in glucose detection was obtained by replacing the $\mathrm{TiO}_{2}$ films with $\mathrm{TiO}_{2}$ nanotubes ( $\mathrm{Zhu}$ et al., 2015). The nanotubes were developed using the hydrothermal method and functionalized with $\mathrm{GOx} . \mathrm{TiO}_{2}$ nanorods (Yang et al., 2014) and nanosheets (Liu P. et al., 2017) were tested as glucose sensors after functionalizing with GO. Better LOD was obtained for nanorods morphology $(0.002 \mathrm{mM})$ comparing with nanosheets $(0.01 \mathrm{mM})$ mostly due to higher surface coverage, which was $3.32 \times 10^{-11} \mathrm{~mol} / \mathrm{cm}$. Concluding, the LOD depends mostly on the active surface, which explains why nanotubes give better results compared with $\mathrm{TiO}_{2}$ films.

$\mathrm{TiO}_{2}$ was used for $\mathrm{H}_{2} \mathrm{O}_{2}$ detection in the form of microspheres (Liu H. et al., 2017) or macro-mesoporous film (Wu et al., 2018). The $\mathrm{TiO}_{2}$ microspheres with a bag-like structure were hydrothermally obtained and functionalized with hemoglobin (Hem). The amperometric measurements indicate a LOD of $10 \mathrm{nM}$. This value is considerably lower compared with $\mathrm{TiO}_{2}$ mesoporous films $(1.65 \mu \mathrm{M}$ LOD) obtained by doctor blade technique and functionalized with horseradish peroxidase (HPOx).

Anodization of titanium was intensively used to obtain $\mathrm{TiO}_{2}$ nanotubes for $\mathrm{H}_{2} \mathrm{O}_{2}$ (Kafi et al., 2011), cholesterol (Khaliq et al., 2020) and breast cancer cell (Safavipour et al., 2020) detection. When the $\mathrm{TiO}_{2}$ nanotubes were functionalized with Hem the LOD evaluated by amperometry was $0.08 \mu \mathrm{M}$. Better LOD value was obtained for cholesterol detection $(0.05 \mu \mathrm{M})$ based on a non-enzymatic approach to the oxidation process. Finally, $\mathrm{TiO}_{2}$ nanotubes were 
TABLE 1 | Representative studies on metal oxide semiconductors used in biosensors.

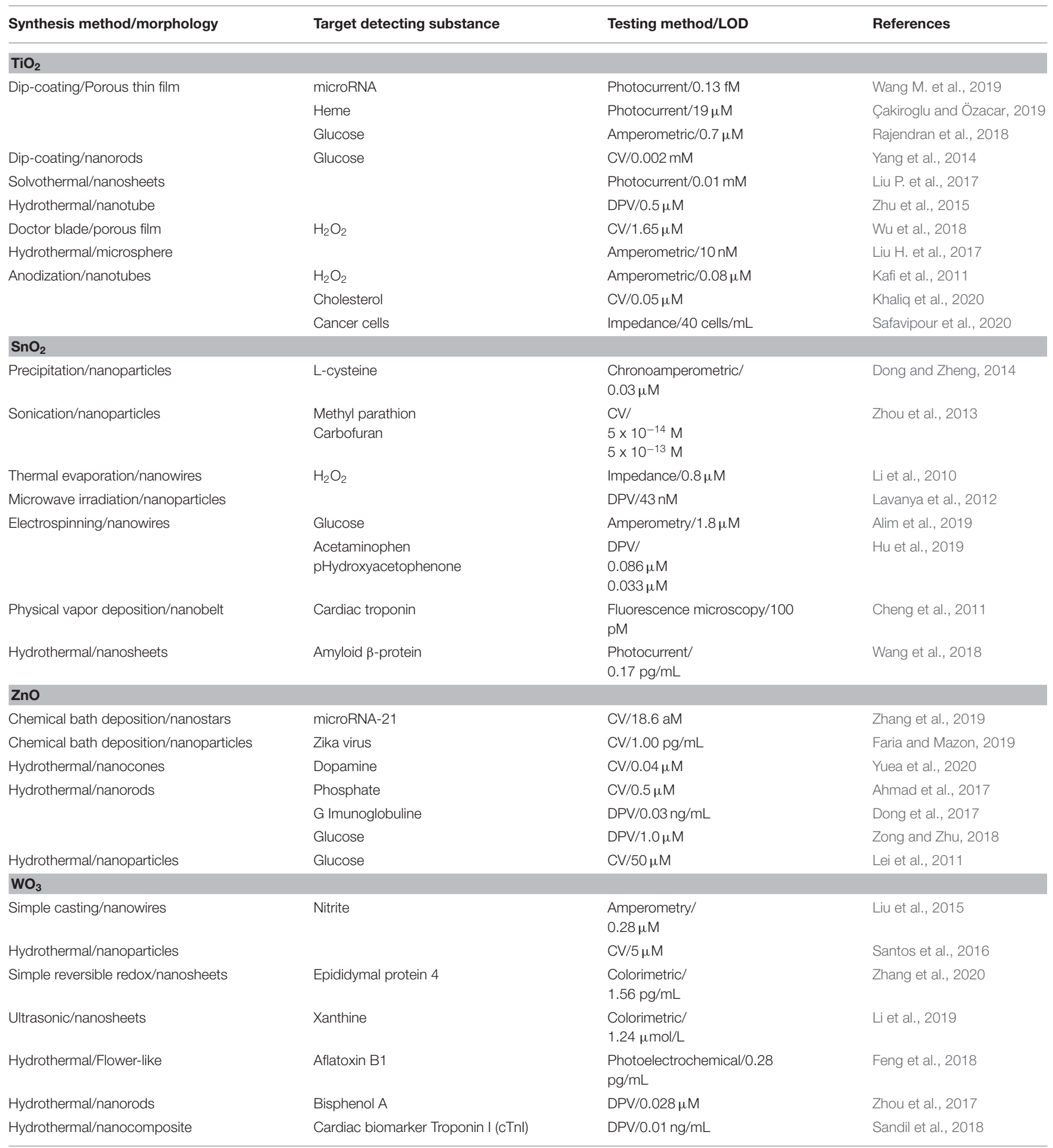

functionalized with human mucin-1 aptamers, inducing sensitive electrochemical detection of breast cancer cells (MCF-7). In this case the 40 cells/mL LOD represent an encouraging result for future biomedical $\mathrm{TiO}_{2}$ application in breast cancer detection.

\section{$\mathrm{SnO}_{2}$-based Biosensors}

Due to features such as high surface area, good biocompatibility, nontoxicity, excellent chemical stability, and catalytic activity, $\mathrm{SnO}_{2}$ was used in many applications such as light energy conversion, biosensors, smart windows, and electrochemistry. 
Tin oxide is an n-type semiconductor with a wide band gap of $3.8 \mathrm{eV}$ and rutile structure (see Figure 1).

$\mathrm{SnO}_{2}$ nanoparticles were synthesized by precipitation (Dong and Zheng, 2014), sonication (Zhou et al., 2013) and microwave irradiation (Lavanya et al., 2012). By using precipitation method, the $\mathrm{SnO}_{2}$ nanoparticles have an average diameter of $4 \mathrm{~nm}$ and were used for L-cysteine detection. In order to employ the chronoamperometric detection method, the $\mathrm{SnO}_{2}$ surface was coated with multiwall carbon nanotubes giving a LOD of $0.03 \mu \mathrm{M}$. The $\mathrm{SnO}_{2}$ nanoparticles obtained by sonication methods were used for pesticide detection based on acetylcholinesterase as a functionalize agent. The LOD evaluated by cyclic voltametry $(\mathrm{CV})$ was $5 \times 10^{-14}$ for methyl parathion and $5 \times 10^{-13}$ for carbofuran. The microwave irradiation method was employed to obtain $\mathrm{SnO}_{2}$ nanoparticles with application for $\mathrm{H}_{2} \mathrm{O}_{2}$ detection. $\mathrm{SnO}_{2}$ surface was functionalized with $\mathrm{HPOx}$ and, based on differential pulse voltammetry (DPV), a LOD of $43 \mathrm{nM}$ was obtained.

An $\mathrm{H}_{2} \mathrm{O}_{2}$ sensor was developed using $\mathrm{SnO}_{2}$ nanowires synthesized by the thermal evaporation method (Li et al., 2010). Using the same functionalizing molecule as $\mathrm{SnO}_{2}$ nanoparticles, the LOD measured by $\mathrm{CV}$ was $0.8 \mu \mathrm{M}$. $\mathrm{SnO}_{2}$ nanowires were also obtained by the electrospinning method (Alim et al., 2019) for glucose amperometric detection. In this case the functionalizing procedure was done with both $\mathrm{HPOx}$ and GOx, giving a LOD of $1.8 \mu \mathrm{M}$. $\mathrm{SnO}_{2}$ nanobelts (Cheng et al., 2011) and nanosheets (Wang et al., 2018) were obtained by physical evaporation deposition, respectively using hydrothermal methods. The nanobelts functionalized with D-biotin molecules were successfully used as a troponin I detector, a protein marker for myocardial infarction (100 pM LOD). The nanosheets were used for amyloid $\beta$-protein $(\mathrm{A} \beta)$ detection after a previous functionalizing procedure with anti- $\mathrm{A} \beta$ antibody. Based on photocurrent measurements the LOD value was $0.17 \mathrm{pg} / \mathrm{mL}$, considered as promising for applications in the detection of disease-related biomarkers.

\section{ZnO-based Biosensors}

$\mathrm{ZnO}$ is a direct wide band gap semiconductor which under UV radiation exhibits $n$-type conductivity. During the crystallization forms a hexagonal wurtzite structure (see Figure 1) which has particular piezoelectric properties based on noncentrosymmetric crystal structures. The major part of the $\mathrm{ZnO}$ synthesis procedures are wet techniques. Compared with tin oxide, $\mathrm{ZnO}$ has a better binding ability with biological entities, which is a prerequisite for future biosensor applications in medicine. Due to its nontoxicity and compatibility with human skin, $\mathrm{ZnO}$ can be adapted as a permanent human sensor in chronic diseases such as diabetes.

Chemical bath deposition (CBD) has been used (Zhang et al., 2019) to obtain $\mathrm{ZnO}$ nanostars for detecting microRNA21 in cancer cells. Previously, the surface was functionalized using thiol-modified hairpin and hybridization chain reactions, considering the development of electrochemiluminescence (ECL) biosensors. The LOD was evaluated at $18.6 \mathrm{aM}$, which makes this material a good candidate for clinical bioassay. The same technique was also employed (Faria and Mazon, 2019) to develop $\mathrm{ZnO}$ nanoparticles for detection of Zika virus in undiluted urine. The Zika virus is transmitted through mosquito bites and gives symptoms such as headaches, arthralgia, myalgia, or conjunctivitis (Faria and Mazon, 2019). The ZIKV-NS1 antibody was immobilized using cystamine and glutaraldehyde on the $\mathrm{ZnO}$ nanoparticles. The LOD was evaluated using CV and the result was $1.00 \mathrm{pg} / \mathrm{mL}$. This MOS biosensor can be used in early detection of the Zika virus.

Another technique that has been extensively used for $\mathrm{ZnO}$ synthesis with biosensing application is the hydrothermal procedure. Both $\mathrm{ZnO}$ nanorods (Zong and $\mathrm{Zhu}, 2018$ ) and nanoparticles (Lei et al., 2011) hydrothermally obtained were used in biosensors for glucose detection. The $\mathrm{ZnO}$ nanorods where functionalized with GOx by simple immersion and the LOD via DPV was $1.0 \mu \mathrm{M}$. These results are significantly better compared with $\mathrm{ZnO}$ nanopowder functionalized with GOx, where LOD was $50 \mu \mathrm{M}$. $\mathrm{ZnO}$ nanorods where hydrothermally obtained and used as sensors for phosphate (Ahmad et al., 2017) and G Imunoglobuline (Dong et al., 2017) detection. For phosphate detection the $\mathrm{ZnO}$ was functionalized with pyruvate oxidase by immersion, and the LOD was $0.5 \mu \mathrm{M}$. In order to develop a $\mathrm{G}$ Imunoglobuline sensor with $0.03 \mathrm{ng} / \mathrm{mL}$ $\mathrm{LOD}$, the $\mathrm{ZnO}$ surface was functionalized with myoglobin by immersion and cold drying. $\mathrm{ZnO}$ nanocone arrays were developed using the hydrothermal technique (Yuea et al., 2020) for dopamine detection. The nanocones were functionalized using Au nanoparticles with carboxyl groups obtaining a sensor with high sensitivity $(4.36 \mu \mathrm{A} / \mu \mathrm{M})$ and low LOD $(0.04 \mu \mathrm{M})$.

\section{$\mathrm{WO}_{3}$-based Biosensors}

$\mathrm{WO}_{3}$ is an n-type semiconductor with a band gap of $2.8 \mathrm{eV}$ and a versatile crystalline structure varying from cubic to octahedral, depending on the synthesis temperature. High surface to volume ratio $\mathrm{WO}_{3}$-based materials can be developed using physical and chemical techniques with well-controlled dimensionality, sizes, and crystal structure for sensors research.

$\mathrm{A} \mathrm{WO}_{3}$ nitrite-based sensor was prepared by a simple casting (Liu et al., 2015) and hydrothermal (Santos et al., 2016) methods. In the first case $\mathrm{WO}_{3}$ has nanowire morphology and was functionalized with hemoglobin, while $\mathrm{WO}_{3}$ nanoparticles were obtained and functionalized with cytochrome $\mathrm{c}$ nitrite reductase using the hydrothermal procedure. The LOD value in the case of $\mathrm{WO}_{3}$ nanowire is significantly lower $(0.28 \mu \mathrm{M})$ compared with WO3 nanopowder $(5 \mu \mathrm{M})$ underlining the significance of semiconductor morphology, synthesis and functionalizing procedures. The hydrothermal method has been used to produce $\mathrm{WO}_{3}$ sensors with different morphologies: flower-like for aflatoxin B1 (Feng et al., 2018), nanorods for bisphenol A (Zhou et al., 2017), and nanosheets for cardiac biomarker Troponin I (Sandil et al., 2018). The $\mathrm{WO}_{3}$ flower-like morphology was functionalized with bovine serum albumin and the LOD corresponding to aflatoxin B1 was very low $(0.28 \mathrm{pg} / \mathrm{mL})$. The nanorods were doped with $\mathrm{Na}^{+}$ions, giving a LOD value of $0.028 \mu \mathrm{M}$. Finally, the nanosheets were functionalized with 3aminopropyl tri-ethoxy saline for the activation of amino groups and the LOD value was $0.01 \mathrm{ng} / \mathrm{mL}$. In the case of WO3-based biosensors the nanosheets morphology gives a better LOD for 
cardiac biomarker Troponin I compared with the flower-like morphology used for alfatoxin $\mathrm{B} 1$ detection.

Other techniques were used to obtain $\mathrm{WO}_{3}$ nanosheets, such as simple reversible redox (Zhang et al., 2020) and ultrasonic exfoliation (Li et al., 2019) processes. Using the reversible redox process makes it possible to develop $\mathrm{WO}_{3}$ nanosheets with an average width of $150 \mathrm{~nm}$, and LOD for human epididymal protein 4 detection of $1.56 \mathrm{pg} / \mathrm{mL}$. Ultrasonic exfoliation of bulk $\mathrm{WO}_{3}$ in water allows the preparation of $\mathrm{WO}_{3}$ nanosheets in the range of 20 to $40 \mathrm{~nm}$. These nanosheets were functionalized with 3, 3', 5, $5^{\prime}$-tetramethylbenzidine and the LOD for xanthine in urine (based on colorimetric evaluation) was 1.24 $\mu \mathrm{mol} / \mathrm{L}$.

\section{CONCLUSIONS}

Metal oxides are considered as versatile materials that can be successfully integrated in biosensor technology. Based on features such as chemical stability, light excitation/light conversion, and high surface-to-volume ratio, these materials are highly competitive in the biosensors market. This mini review has outlined that the biosensors' LOD depends on many

\section{REFERENCES}

Ahmad, R., Ahn, M. S., and Hahn, Y. B. (2017). ZnO nanorods array based field-effect transistor biosensor for phosphate detection. J. Colloid Interf. Sci. 498, 292-297. doi: 10.1016/j.jcis.2017. 03.069

Alim, S., Kafi, A. K. M., Rajan, J., and Yusoff, M. M. (2019). Application of polymerized multiporous nanofiber of $\mathrm{SnO}_{2}$ for designing a bienzyme glucose biosensor based on HRP/Gox. Int. J. Biol. Macromol. 123, 1028-1034. doi: 10.1016/j.ijbiomac.2018.11.171

Çakiroglu, B., and Özacar, M. (2019). A self-powered photoelectrochemical biosensor for $\mathrm{H}_{2} \mathrm{O}_{2}$, and xanthine oxidase activity based on enhanced chemiluminescence resonance energy transfer through slow light effect in inverse opal $\mathrm{TiO}_{2}$. Biosens. Bioelectron. 141:111385. doi: $10.1016 /$ j.bios.2019.111385

Cao, S. P., Hu, H. M., Liang, R. P., and Qiu, J. D. (2020). An ultrasensitive electrochemiluminescence resonance energy transfer biosensor for divalent mercury monitoring. J. Electroanal. Chem. 856:113494. doi: 10.1016/j.jelechem.2019.113494

Chen, D., Lv, L., Peng, L., Peng, J., and Tu, J. (2019). Controlled synthesis of mesoporous zinc oxide containing oxygen vacancies in low annealing temperature for photoelectrochemical biosensor. Ceram. Int. 45, 18044-18051. doi: 10.1016/j.ceramint.2019.06.024

Cheng, Y., Chen, K. S., Meyer, N. L., Yuan, J., Hirst, L. S., Chase, P. B., et al. (2011). Functionalized $\mathrm{SnO}_{2}$ nanobelt field-effect transistor sensors for label-free detection of cardiac troponin. Biosens. Bioelectron. 26, 4538-4544. doi: 10.1016/j.bios.2011.05.019

Dong, S., Tong, M., Zhang, D., and Huang, T. (2017). The strategy of nitrite and immunoassay human IgG biosensors basedon ZnO@ZIF-8 and ionic liquid composite film. Sens. Actuat. B-Chem. 251, 650-657. doi: 10.1016/j.snb.2017.05.047

Dong, Y., and Zheng, J. (2014). A nonenzymatic L-cysteine sensor based on $\mathrm{SnO}_{2}$-MWCNTs nanocomposites. J. Mol. Liq. 196, 280-284. doi: 10.1016/j.molliq.2014.03.046

Elahi, N., Kamali, M., Baghersad, M. H., and Amini, B. (2019). A fluorescence nano-biosensors immobilization on iron (MNPs) and gold (AuNPs) nanoparticles for detection of Shigella spp. Mater. Sci. Eng. C 105:110113. doi: 10.1016/j.msec.2019.110113 parameters such as: morphology (active surface), functionalizing molecule, evaluation procedure, and detecting target. The same material with similar morphology and detecting targets can give different LOD depending on surface functionalization and evaluation procedures. Even if most of the biosensors are used for glucose $\left(\mathrm{H}_{2} \mathrm{O}_{2}\right.$, uric acid) there are encouraging results for cancer cell or virus detection. Recent advancements indicate a promising future for MOS in applications such as skin bioelectronics, neural interfaces, and smart biosensing devices. However, much effort is required to overcome important issues related to optimizing organic/inorganic interface compatibility, the enzyme electrochemistry at the MOS interface, and LOD improvement. To achieve this goal, facile MOS synthesis technologies allowing good interface control must be implemented.

\section{AUTHOR CONTRIBUTIONS}

IŞ was responsible for article database regarding $\mathrm{TiO}_{2}, \mathrm{SnO}_{2}$, and $\mathrm{WO}_{3}$, including Table 1. AE has coordinated the writing, introduction, biosensors mechanism (including Figure 1), and article database for $\mathrm{ZnO}$.

Enesca, A., Andronic, L., and Duta, A. (2012a). Optimization of opto-electrical and photocatalytic properties of $\mathrm{SnO}_{2}$ thin films using $\mathrm{Zn}^{2+}$ and $\mathrm{W}^{6+}$ dopant ions. Catal. Lett. 142, 224-230. doi: 10.1007/s10562-011-0762-4

Enesca, A., Andronic, L., and Duta, A. (2012b). The influence of surfactants on the crystalline structure, electrical and photocatalytic properties of hybrid multistructured $\left(\mathrm{SnO}_{2}, \mathrm{TiO}_{2}\right.$ and $\left.\mathrm{WO}_{3}\right)$ thin films. Appl. Surf. Sci. 258, 4339-4346. doi: $10.1016 / j . a p s u s c .2011 .12 .110$

Enesca, A., Isac, L., and Duta, A. (2015). Charge carriers injection in tandem semiconductors for dyes mineralization. Appl. Catal. B Environ. 162, 352-363. doi: 10.1016/j.apcatb.2014.06.059

Faria, A. M., Mazon, T. (2019). Early diagnosis of zika infection using a $\mathrm{ZnO}$ nanostructures-based rapid electrochemical biosensor. Talanta 203, 153-160. doi: 10.1016/j.talanta.2019.04.080

Feizabadi, M., Soleymanpour, A., Faridnouri, H., and Ajloo, D. (2019). Improving stability of biosensor based on covalent immobilization of horseradish peroxidase by $\gamma$-aminobutyric acid and application in detection of $\mathrm{H}_{2} \mathrm{O}_{2}$. Int. J. Biol. Macromol. 136, 597-606. doi: 10.1016/j.ijbiomac.2019.06.103

Feng, J., Li, Y., Gao, Z., Lv, H., Zhang, H., Dong, Y., et al. (2018). A competitivetype photoelectrochemical immunosensor for aflatox in $\mathrm{B} 1$ detection based on flower-like $\mathrm{WO}_{3}$ as matrix and $\mathrm{Ag}_{2} \mathrm{~S}$-enhanced $\mathrm{BiVO}_{4}$ for signal amplification. Sens. Actuat. B-Chem. 270, 104-111. doi: 10.1016/j.snb.2018.05.015

Fiorani, A., Merino, J. P., Zanut, A., Criado, A., and Paolucci, F. (2019). Advanced carbon nanomaterials for electrochemiluminescent biosensor applications. Curr. Opin. Electrochem. 16, 66-74. doi: 10.1016/j.coelec.2019.04.018

Ge, L., Liu, Q., Jiang, D., Ding, L., and Wang, K. (2019). Oxygen vacancy enhanced photoelectrochemical performance of $\mathrm{Bi}_{2} \mathrm{MoO}_{6} / \mathrm{B}, \mathrm{N}$ co-doped graphene for fabricating lincomycin aptasensor. Biosens. Bioelectron. 135, 145-152. doi: 10.1016/j.bios.2019.04.022

Gupta, S., Sharma, A., and Verma, R. S. (2020). Polymers in biosensor devices for cardiovascular applications. Curr. Opin. Biomed. Eng. 13, 69-75. doi: 10.1016/j.cobme.2019.10.002

Han, S., Zhang, Q., Zhang, X., Liu, X., and Zheng, G. (2019). A digital microfluidic diluter-based microalgal motion biosensor for marine pollution monitoring. Biosens. Bioelectron. 143:111597. doi: 10.1016/j.bios.2019.111597

Hernández-Cancel, G., Suazo-Dávila, D., Medina-Guzmán, J., Rosado-González, M., and Griebenow, K. (2015). Chemically glycosylation improves the stability of an amperometric horseradish peroxidase biosensor. Anal. Chim. Acta 854, 129-139. doi: 10.1016/j.aca.2014.11.008 
Hocini, A., Temmar, M. N., Khedrouche, D., and Zamani, M. (2019). Novel approach for the design and analysis of a terahertz microstrip patch antenna based on photonic crystals. Photonics Nanostruct. 36:100723. doi: 10.1016/j.photonics.2019.100723

Hu, W., Zhang, Z., Li, L., Ding, Y., and An, J. (2019). Preparation of electrospun $\mathrm{SnO}_{2}$ carbon nanofiber composite for ultrasensitive detection of APAP and p-Hydroxyacetophenone. Sens. Actuat. B. 299:127003. doi: $10.1016 / j . s n b .2019 .127003$

Huang, Q., Wang, Y., Lei, L., Xu, Z., and Zhang, W. (2016). Photoelectrochemical biosensor for acetylcholinesterase activity study based on metal oxide semiconductor nanocomposites. J. Electroanal. Chem.781, 377-382. doi: 10.1016/j.jelechem.2016.07.007

Kafi, A. K. M., Wu, G., Benvenuto, P., and Chen, A. (2011). Highly sensitive amperometric $\mathrm{H}_{2} \mathrm{O}_{2}$ biosensor based on hemoglobin modified $\mathrm{TiO}_{2}$ nanotubes. J. Electroanal. Chem. 662, 64-69. doi: 10.1016/j.jelechem.2011.03.021

Kao, C. H., Chen, H., Yao, F., Hou, S., Chang, S. W., and Lin, M. H. (2015). Fabrication of multianalyte $\mathrm{CeO}_{2}$ nanograin electrolyte-insulatorsemiconductor biosensors by using $\mathrm{CF}_{4}$ plasma treatment, sensing and biosensing Res. 5, 71-77. doi: 10.1016/j.sbsr.2015.07.001

Khaliq, N., Rasheed, M. A., Cha, G., Khan, M., Karim, S., Schmuki, P., et al. (2020). Development of non-enzymatic cholesterol bio-sensor based on TiO2 nanotubes decorated with Cu2O nanoparticles. Sens. Actuat. B 302:127200. doi: $10.1016 /$ j.snb.2019.127200

Lavanya, N., Radhakrishnan, S., and Sekar, C. (2012). Fabrication of hydrogen peroxide biosensor based on $\mathrm{Ni}$ doped $\mathrm{SnO}_{2}$ nanoparticles. Biosens. Bioelectron. 36, 41-47. doi: 10.1016/j.bios.2012.03.035

Lei, Y., Yan, X., Zhao, J., Liu, X., Song, Y., Luo, N., et al. (2011). Improved glucose electrochemical biosensor by appropriate immobilization of nanoZnO, Colloid. Surface. B 82, 168-172. doi: 10.1016/j.colsurfb.2010.08.034

Li, L., Huang, J., Wang, Y., Zhang, H., Liu, Y., And Li, J. (2010). An excellent enzyme biosensor based on Sb-doped $\mathrm{SnO}_{2}$ nanowires. Biosens. Bioelectron. 25, 2436-2441. doi: 10.1016/j.bios.2010.03.037

Li, Z., Liu, X., Liang, X. H., Zhong, J., Guo, L., and Fu, F. (2019). Colorimetric determination of xanthine in urine based on peroxidase-like activity of $\mathrm{WO}_{3}$ nanosheets. Talanta 204, 278-284. doi: 10.1016/j.talanta.2019.06.003

Liu, C. H., Hong, M. H., Lum, M. C., Flotow, H., Ghadessy. F., and Zhang, J. B. (2010). Large-area micro/nanostructures fabrication in quartz by laser interference lithography and dry etching. Appl. Phy. A. 101, 237-241. doi: 10.1007/s00339-010-5807-9

Liu, H., Duan, C., Yang, C., Chen, X., Shen, W., and Zhu, Z. (2015). A novel nitrite biosensor based on the direct electron transfer hemoglobin immobilized in the $\mathrm{WO}_{3}$ nanowires with high length-diameter ratio. Mater. Sci. Eng. C 53, 43-49. doi: 10.1016/j.msec.2015.04.016

Liu, H., Guo, K., Duan, C., Dong, X., and Gao, J. (2017). Hollow $\mathrm{TiO}_{2}$ modified reduced graphene oxide microspheres encapsulating hemoglobin for a mediator-free biosensor. Biosens. Bioelectron. 87, 473-479. doi: 10.1016/j.bios.2016.08.089

Liu, P., Huo, X., Tang, Y., Xu, J., Liu, X., and Wong, K. Y. (2017). A TiO ${ }_{2}$ nanosheet$\mathrm{g}_{-} \mathrm{C}_{3} \mathrm{~N}_{4}$ composite photoelectrochemical enzyme biosensor excitable by visible irradiation. Anal. Chim. Acta 984, 86-95. doi: 10.1016/j.aca.2017.06.043

Mihaly, M., Lacatusu, I., Enesca, A., and Meghea, A. (2008). Hybride nanomaterials based on silica coated C-60 clusters obtained by microemulsion technique. Mol. Cryst. Liq. Cryst. 483, 205-215. doi: 10.1080/15421400801906885

Oh, J., Yoo, G., Chang, Y. W., Kim, H. J., and Yoo, K. H. (2013). A carbon nanotube metal semiconductor field effect transistor-based biosensor for detection of amyloid-beta in human serum. Biosens. Bioelectron. 50, 345-350. doi: 10.1016/j.bios.2013.07.004

Ortiz, E., Gallay, P., Galicia, L., Eguílaz, M., and Rivas, G. (2019). Nanoarchitectures based on multi-walled carbon nanotubes non-covalently functionalized with Concanavalin A: a new building-block with supramolecular recognition properties for the development of electrochemical biosensors. Sens. Actuat. B-Chem. 292, 254-262. doi: 10.1016/j.snb.2019.04.114

Osman, D. I., El-Sheikh, S. M., Sheta, S. M., Ali, O. I., and Shawky, S. M. (2019). Nucleic acids biosensors based on metal-organic framework (MOF): paving the way to clinical laboratory diagnosis. Biosens. Bioelectron. 141:111451. doi: 10.1016/j.bios.2019.111451
Rajendran, S., Manoj, D., Raju, K., Dionysiou, D. D., Naushad, M., Gracia, F., et al. (2018). Influence of mesoporous defect induced mixed-valent $\mathrm{NiO}$ $\left(\mathrm{Ni}^{2+} / \mathrm{Ni}^{3+}\right)-\mathrm{TiO}_{2}$ nanocomposite for non-enzymatic glucose biosensors. Sens. Actuat. B 264, 27-37. doi: 10.1016/j.snb.2018.02.165

Ramon-Marquez, T., Medina-Castillo, A. L., Fernandez-Gutierrez, A., and Fernandez-Sanchez, J. F. (2018). Evaluation of two sterically directed attachments of biomolecules on a coaxial nanofibre membrane to improve the development of optical biosensors. Talanta 187, 83-90. doi: 10.1016/j.talanta.2018.05.004

Rathinamala, I., Jeyakumaran, N., and Prithivikumaran, N. (2019). Sol-gel assisted spin coated CdS/PS electrode based glucose biosensor. Vacuum 161, 291-296. doi: 10.1016/j.vacuum.2018.12.045

Rezaei, H., Motovali-bashi, M., and Radfar, S. (2019). An enzyme-free electrochemical biosensor for simultaneous detection of two hemophilia A biomarkers: Combining target recycling with quantum dots-encapsulated metal-organic frameworks for signal amplification. Anal. Chim. Acta 1092, 66-74. doi: 10.1016/j.aca.2019.09.037

Safavipour, M., Kharaziha, M., Amjadi, E., Karimzadeh, F., and Allafchian, A. (2020). TiO2 nanotubes/reduced GO nanoparticles for sensitive detection of breast cancer cells and photothermal performance, Talanta 208:120369. doi: 10.1016/j.talanta.2019.120369

Sandil, D., Srivastava, S., Malhotra, B. D., Sharma, S. C., and Puri, N. K. (2018). Biofunctionalized tungsten trioxide-reduced graphene oxide nanocomposites for sensitive electrochemical immunosensing of cardiac biomarker. J. Alloy. Compd. 763, 102-110. doi: 10.1016/j.jallcom.2018.04.293

Santos, L., Silveira, C. M., Elangovan, E., Neto, J. P., Nunes, D., Pereira, L., et al. (2016). Synthesis of $\mathrm{WO}_{3}$ nanoparticles for biosensing applications. Sens. Actuat. B-Chem. 223, 186-194. doi: 10.1016/j.snb.2015.09.046

Scognamiglio, V., Antonacci, A., Arduini, F., Moscone, D., and Palleschi, G. (2019). An eco-designed paper-based algal biosensor for nanoformulated herbicide optical detection. J. Hazard. Mater. 373, 483-492. doi: 10.1016/j.jhazmat.2019.03.082

Solaimuthu, A., Vijayan, A. N., Murali, P., and Korrapati, P. S. (2020). Nanobiosensors and their relevance in tissue engineering, Curr. Opin. Biomed. Eng. 13, 84-93. doi: 10.1016/j.cobme.2019.12.005

Soldatkina, O. V., Soldatkin, O. O., Velychko, T. P., Prilipko, V. O., and Dzyadevych, S. V. (2018). Conductometric biosensor for arginine determination in pharmaceutics. Bioelectrochemistry 124, 40-46. doi: 10.1016/j.bioelechem.2018.07.002

Song, H., Zhang, Y., Wang, S., Huang, K., and Xu, W. (2020). Label-free polygonalplate fluorescent-hydrogel biosensor for ultrasensitive microRNA detection. Sensor. Actuat. B-Chem. 306:27554. doi: 10.1016/j.snb.2019.127554

Visa, M., Andronic, L., and Enesca, A. (2016). Behavior of the new composites obtained from fly ash and titanium dioxide in removing of the pollutants from wastewater. Appl. Surf. Sci. 388, 359-369. doi: 10.1016/j.apsusc.2015.12.154

Wang, M., Yin, H., Zhou, Y., Sui, C., Wang, Y., Meng, X., et al. (2019). Photoelectrochemical biosensor for microRNA detection based on a $\mathrm{MoS}_{2} / \mathrm{g}-\mathrm{C}_{3} \mathrm{~N}_{4} /$ black $\mathrm{TiO}_{2}$ heterojunction with Histostar@AuNPs for signal Amplification. Biosens. Bioelectron. 128, 137-143. doi: $10.1016 /$ j.bios.2018.12.048

Wang, Q., Zhao, Y., Yang, Q., Du, D., and Lin, Y. (2019). Amperometric sarcosine biosensor with strong anti-interference capabilities based on mesoporous organic-inorganic hybrid materials. Biosens. Bioelectron. 141:111431. doi: 10.1016/j.bios.2019.111431

Wang, Y., Fan, D., Zhao, G., Feng, J., Wei, D., Zhang, N., et al. (2018). Ultrasensitive photoelectrochemical immunosensor for the detection of amyloid $\beta$-protein based on $\mathrm{SnO}_{2} / \mathrm{SnS}_{2} / \mathrm{Ag} 2 \mathrm{~S}$ nanocomposites. Biosens. Bioelectron. 120, 1-7. doi: 10.1016/j.bios.2018.08.026

Wang, Y. H., Huang, K. J., and Wu, X. (2017). Recent advances in transitionmetal dichalcogenides based electrochemical biosensors: a review. Biosens. Bioelectron. 97, 305-316. doi: 10.1016/j.bios.2017.06.011

Wu, X., Zhang, H., Huang, K., Zeng, Y., and Zhu, Z. (2018). Rose petal and P123 dual-templated macro-mesoporous $\mathrm{TiO}_{2}$ for a hydrogen peroxide biosensor. Bioelectrochemistry 120, 150-156. doi: 10.1016/j.bioelechem.2017. 12.009

Xu, B., Huang, J., Ding, L., and Cai, J. (2020). Graphene oxide-functionalized long period fiber grating for ultrafast label-free glucose biosensor. Mater. Sci. Eng. C 107:110329. doi: 10.1016/j.msec.2019.110329 
Yang, Z., Tang, Y., Li, J., Zhang, Y., and Hu, X. (2014). Facile synthesis of tetragonal columnar-shaped $\mathrm{TiO}_{2}$ nanorods for the construction of sensitive electrochemical glucose biosensor. Biosens. Bioelectron. 54, 528-533. doi: 10.1016/j.bios.2013.11.043

Yi, Y., Xie, B., Zhao, T., Qian, Z., and Liu, H. (2020). The effect of anode hydrodynamics on the sensitivity of microbial fuel cell based biosensors and the biological mechanism. Bioelectrochemistry 132:107351. doi: 10.1016/j.bioelechem.2019.107351

Yilmaz, Y. Y., Yalcinkaya, E. E., Demirkol, D. O., and Timur, S. (2020). 4-aminothiophenol-intercalated montmorillonite: Organic-inorganic hybrid material as an immobilization support for biosensors. Sens. Actuat. B-Chem. 307:127665. doi: 10.1016/j.snb.2020.127665

Yin, M.-J., Gu, B., An, Q.-F., Yang, C., and Yong, K.-T. (2018). Recent development of fiber-optic chemical sensors and biosensors: Mechanisms, materials, micro/nano-fabrications and applications. Coordin. Chem. Rev. 376, 348-392. doi: 10.1016/j.ccr.2018.08.001

Yoo, T., Lim, K., Sultan, M. T., Lee, J. S., and Jang, M. (2019). The real-time monitoring of drug reaction in $\mathrm{HeLa}$ cancer cell using temperature/impedance integrated biosensors, Sens. Actuat. B-Chem.291, 17-24. doi: 10.1016/j.snb.2019.03.145

Yuan, Y., Wang, Y., Wang, H., and Hou, S. (2019). Gold nanoparticles decorated on single layer graphene applied for electrochemical ultrasensitive glucose biosensor. J. Electroanal. Chem. 855:113495. doi: 10.1016/j.jelechem.2019.113495

Yuea, H. Y., Zhanga, H. J., Huanga, S., Lua, X. X., Gaoa, X., Songa, S. S., et al. (2020). Highly sensitive and selective dopamine biosensor using Au nanoparticles$\mathrm{ZnO}$ nanocone arrays/graphene foam electrode. Mater. Sci. Eng. C 108:110490. doi: 10.1016/j.msec.2019.110490

Zhang, B., Wang, H., Xi, J., Zhao, F., and Zeng, B. (2020). In situ formation of inorganic/organic heterojunction photocatalyst of $\mathrm{WO} 3 / \mathrm{Au} /$ polydopamine for immunoassay of human epididymal protein 4. Electrochim. Acta 331:135350. doi: 10.1016/j.electacta.2019.135350

Zhang, X., Li, W., Zhou, Y., Chai, Y., and Yuan, R. (2019). An ultrasensitive electrochemiluminescence biosensor for MicroRNA detection based on luminol-functionalized Au NPs@ZnO nanomaterials as signal probe and dissolved $\mathrm{O}_{2}$ as coreactant. Biosens. Bioelectron.135, 8-13. doi: 10.1016/j.bios.2019.04.004

Zhao, D., Liu, Y., Zhang, Q., Zhang, Y., and Sang, S. (2019). Surface stress-based biosensor with stable conductive AuNPs network for biomolecules detection. Appl. Surf. Sci. 491, 443-450. doi: 10.1016/j.apsusc.2019.06.178

Zheng, H., Liu, M., Yan, Z., and Chen, J. (2020). Highly selective and stable glucose biosensor based on incorporation of platinum nanoparticles into polyaniline-montmorillonite hybrid composites. Microchem. J. 152:104266. doi: 10.1016/j.microc.2019.104266

Zhou, Q., Yang, L., Wang, G., and Yang, Y. (2013). Acetylcholinesterase biosensor based on $\mathrm{SnO}_{2}$ nanoparticles-carboxylic graphene-nafion modified electrode for detection of pesticides. Biosens. Bioelectron. 49, 25-31. doi: 10.1016/j.bios.2013.04.037

Zhou, Y., Yang, L., Li, S., and Dang, Y. (2017). A novel electrochemical sensor for highly sensitive detection of bisphenol A based on the hydrothermal synthesized Na-doped $\mathrm{WO}_{3}$ nanorods. Sens. Actuat. B-Chem. 245, 238-246. doi: 10.1016/j.snb.2017.01.034

Zhu, J., Liu, X., Wang, X., Huo, X., and Yan, R. (2015). Preparation of polyaniline- $\mathrm{TiO}_{2}$ nanotube composite for the development of electrochemical biosensors. Sens. Actuat. B 221, 450-457. doi: 10.1016/j.snb.2015. 06.131

Zong, X., and Zhu, R. (2018). ZnO nanorod-based FET biosensor for continuous glucose monitoring. Sens. Actuat. B-Chem. 255, 2448-2453. doi: $10.1016 /$ j.snb.2017.09.037

Conflict of Interest: The authors declare that the research was conducted in the absence of any commercial or financial relationships that could be construed as a potential conflict of interest.

Copyright (c) 2020 Șerban and Enesca. This is an open-access article distributed under the terms of the Creative Commons Attribution License (CC BY). The use, distribution or reproduction in other forums is permitted, provided the original author(s) and the copyright owner(s) are credited and that the original publication in this journal is cited, in accordance with accepted academic practice. No use, distribution or reproduction is permitted which does not comply with these terms. 